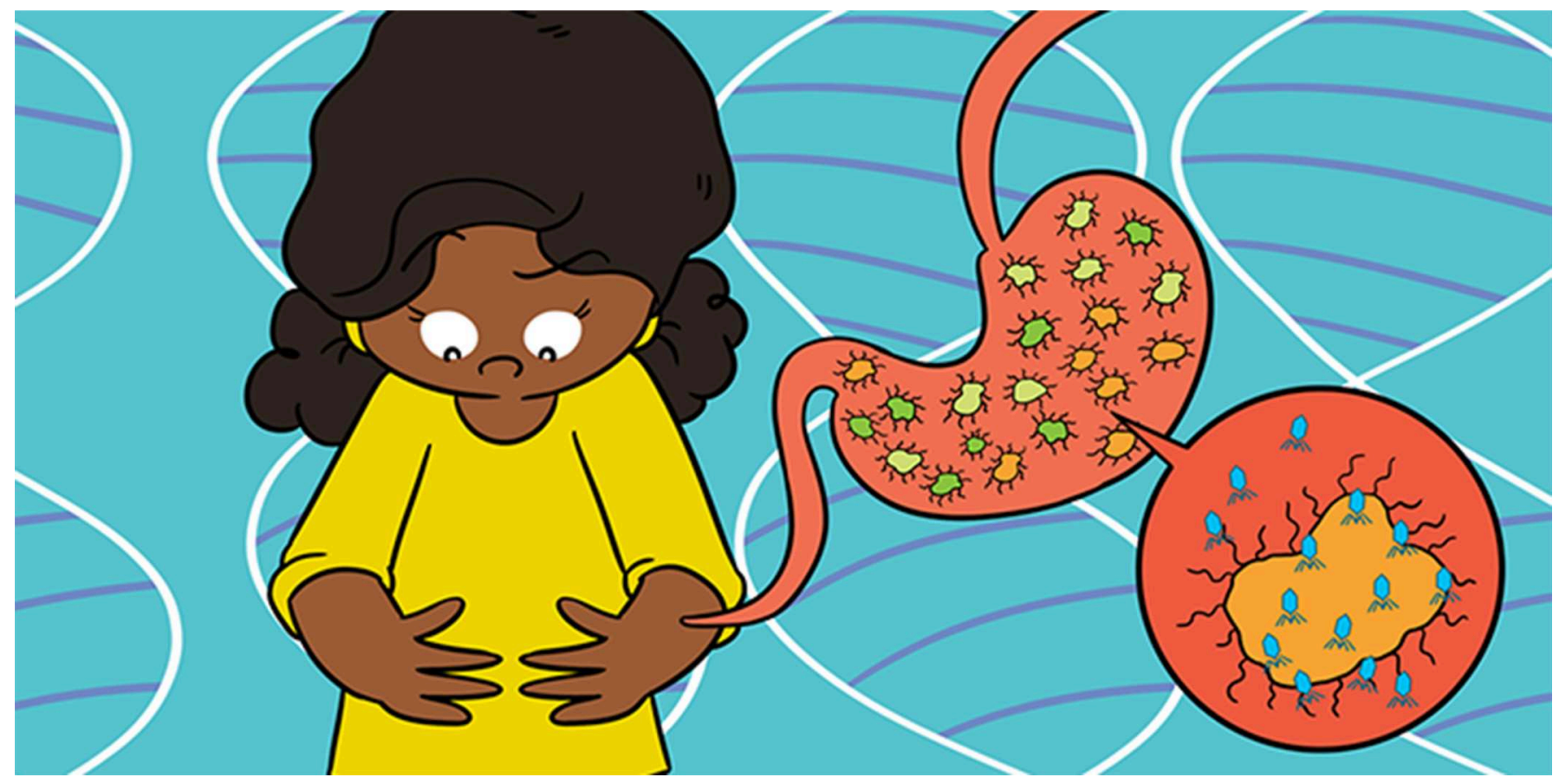

\title{
BACTERIOPHAGES: VIRUSES THAT INFECT BACTERIA
}

\section{Colin Hill ${ }^{*}$}

School of Microbiology and APC Microbiome Ireland, University College Cork, Cork, Ireland

YOUNG REVIEWERS:

JUNALUSKA

ELEMENTARY

SCHOOL

AGE: 15
Bacteria can be infected by tiny viruses called bacteriophages (phages). Bacteriophages are so small they do not even have a single cell, but are instead just a piece of DNA surrounded by a protein coat. When they attack a bacterium, bacteriophages can multiply very quickly until the bacterium bursts and releases lots of new phages. Trillions of bacteria and bacteriophages live in and on the human body and they are vital for a normal, healthy life. We are interested in seeing if we can use phages to help doctors to treat diseases and to help people live healthy lives.

\section{THE MICROBIOME-A NEW HUMAN ORGAN?}

Imagine the excitement if doctors suddenly discovered a new organ in the human body! This is exactly what has happened in the last few years. We now know that, in addition to the lungs, kidneys, brain, liver and heart, we have another organ to consider-the microbiome. This new organ is completely different, because it is made of microbes rather than human cells. Microbes are tiny organisms that include 


\section{BACTERIA}

A type of microbe. A bacterium is a single cell that can divide to form two cells.

VIRUS

A type of microbe that can infects cells. Human viruses infect human cells, plant viruses infect plant cells, etc.

\section{BACTERIOPHAGE}

$A$ virus that infects bacteria, also called a phage.

\section{DNA}

The molecule that carries all the information in the form of genes needed to produce proteins. All organisms get their DNA from their parents. bacteria. One amazing thing about this new organ is that we are born without it. As we are being born, we get bacteria from our mothers and then we continue to add more and more bacteria from the environment, until we have about 1,000 different types of bacteria on and inside our bodies. Bacteria are tiny, but they can multiply very quickly, and within only a few hours, one bacterium can become thousands or even millions of new bacteria. Everyone has a unique microbiome, different from everyone else. We have our microbiomes for our entire lives. The microbiome is mostly located in the gut, but there is also a skin microbiome and a lung microbiome.

But wait-bacteria live with us our whole lives? Most of us think of bacteria as being present only on dirty things, but they are everywhere, including inside of us. Bacteria do not just make us sick-they can do lots of useful jobs, like converting milk into yogurt and cheese, or helping plants to grow. We need the bacteria in our microbiomes to help us to digest our food and to "train" our immune systems, amongst other important roles. Hundreds of laboratories around the world are working to understand the other roles that the microbiome plays in human health. Research has found that people with certain diseases and conditions like Inflammatory Bowel Disease or certain cancers have different microbiomes than healthy people, but it has been difficult to show whether changes in the microbiome are responsible for these diseases. In addition to linking the microbiome to gut and skin problems, recent work has even provided convincing evidence that bacteria in the gut can influence our brains! For example, when researchers transferred the gut microbiome from humans suffering from depression into rats, the animals started to demonstrate behaviors which are also characteristic of depression. The microbiomes from non-depressed humans did not have this effect.

\section{BACTERIOPHAGES-VIRUSES THAT INFECT BACTERIA}

Our microbiomes contain trillions of bacteria living in and on our bodies, but the diversity of life living within us does not stop there. Jonathan Swift was an Irish poet who wrote the lines:

\section{So, naturalists observe, a flea}

Has smaller fleas that on him prey;

And these have smaller still to bite 'em,

And so proceed ad infinitum.

Swift had never heard of the microbiome, but he described it perfectly. We have bacteria that live on us, and bacteria have bacterial viruses that live on them (Figure 1). These viruses are called bacteriophages (or phages). Viruses differ from bacteria in that they are not made of cells, but instead consist of a piece of DNA (or RNA) packed within a protein coat. Viruses are so small that we cannot see them with 
Figure 1

Humans contain lots of bacteria in our microbiomes, mostly in the gut. These bacteria can be attacked by bacterial viruses called bacteriophages.

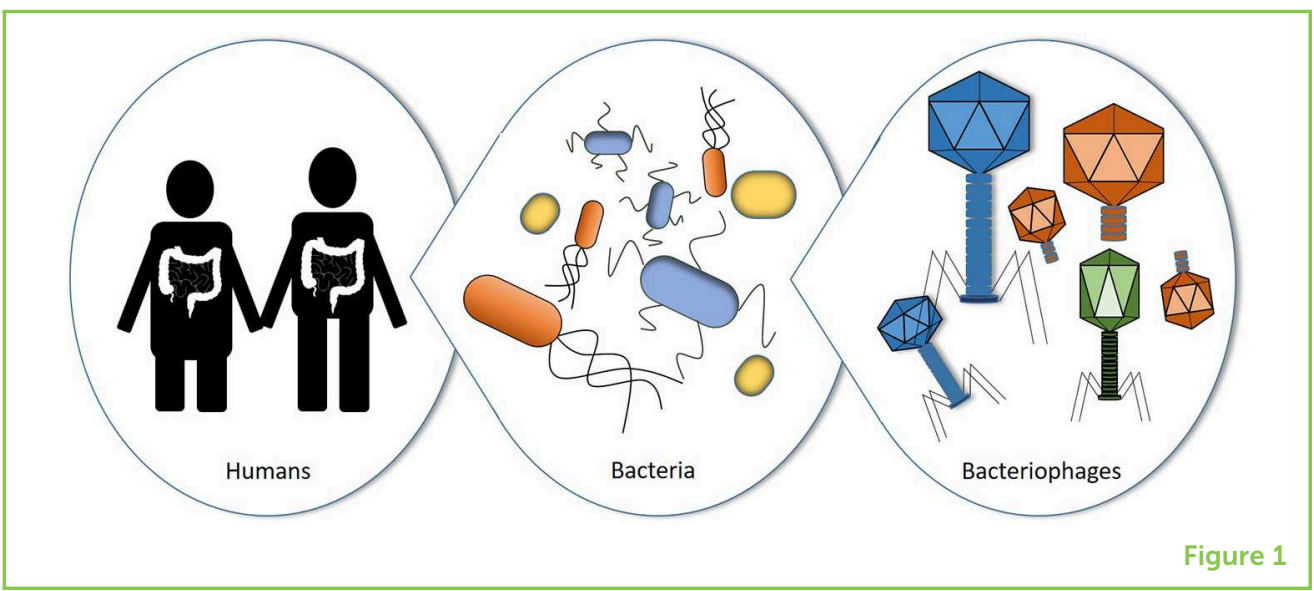

normal microscopes. To give you a sense of their size, if a phage were the size of the period at end of this sentence, then humans would be almost 4 miles $(6 \mathrm{~km})$ tall! Phages are the simplest and most abundant organisms on earth.

Phages are really very beautiful (Figure 2) and the way they reproduce is quite interesting. A phage attaches to a bacterium and injects its DNA into the bacterial cell. The bacterium then turns into a phage factory, producing as many as 100 new phages before it bursts, releasing the phages to attack more bacteria. This means that phages can grow much more quickly than bacteria. In some countries, particularly in Eastern Europe, phages are actually used to treat bacterial infections. Each phage can only kill one type of bacteria, so if a doctor knows what kind of bacteria is infecting a patient, it might be possible to give the patient a phage that can infect and kill that type of bacteria. Phages cannot infect human cells, and so they pose no threat to us.

\section{PHAGES WITHIN US}

We have known for years that lots of phages are present in the gut, but we really did not know very much about them. So, we started to study them. First, we separated the phages away from everything else in the gut, and then we sequenced them. Sequencing allowed us to "read" the phage DNA and predict how many and what types of phages are present. We were amazed to learn that there are tens of thousands of different phages in the human gut. Most of them were completely unknown. Some of the gut phages are very simple and only have three genes, while others are huge and have more than 500 genes.

If there are lots of phages present in the gut and they replicate very quickly, why do they not just wipe out all of the gut bacteria? Well, as is often the case in science, the answer is quite complicated. Sometimes the phage just cannot find its correct bacterial target in the very crowded environment of the gut. Also, bacteria can defend themselves 
Figure 2

Bacteriophages have protein heads and tails, which are packed with DNA. When a phage attacks a bacterium, it injects its DNA. The bacterium them makes more phages that are released when the bacterium bursts.

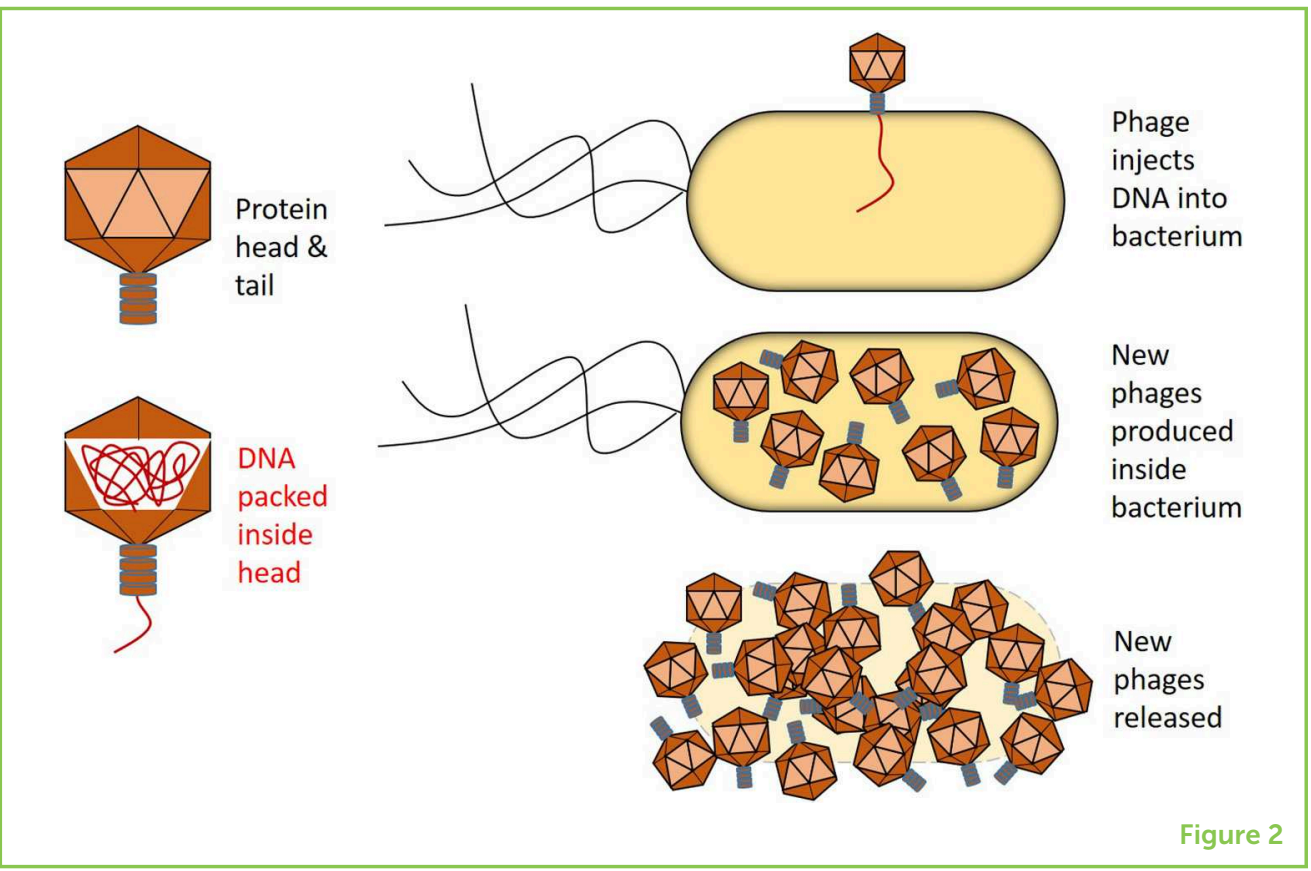

against phages in various ways, including preventing the phage from attaching, chopping up the phage's DNA as it enters the cell, and even taking the drastic step of committing "suicide" to prevent the phage from multiplying and attacking the bacteria's close relatives. As a result, there is a complex balance between phages and bacteria in the gut, and a stable relationship is formed. Bacteria are constantly evolving to combat phages and the phages are also rapidly evolving to overcome bacterial defenses.

\section{WHY IS IT IMPORTANT TO STUDY BACTERIOPHAGES?}

Why are we interested in studying phages in the gut? Why is anyone funding labs like ours and others that are trying to understand these simple yet complex creatures? One excellent reason is that we can learn a lot of fundamental biological principles by studying phages. Quite a few Nobel prizes have been awarded to phage researchers for that very reason. As recently as 2018 the Nobel Prize in Chemistry was awarded to George Smith and Gregory Winter who used the fact that phage grow and mutate quickly to develop new antibodies that have been used to cure many diseases, including some forms of cancer.

Another reason we study phages in the gut is that we hope they might provide us with a very precise way to manipulate or engineer the microbiome. Our hypothesis is that phages are one of the most important parts of the microbiome, and we are designing and performing experiments to test that idea. One thing we are doing is transferring the phage from a healthy microbiome into a microbiome 
that has been damaged by antibiotics, to see if we can restore a healthy microbiome.

Even if our hypothesis turns out to be wrong, we will almost certainly still learn lots of things along the way. But if we are right, then someday doctors might be able to use phages to re-shape the microbiome from an unhealthy to a healthy state, which could possibly help to cure several diseases or disorders. Perhaps by adding very high numbers of phages against a few specific target bacteria, we could change the microbiome in a positive manner. Maybe there will be a time in the future when we can "fix" a damaged microbiome using phages, similar to the way surgeons can currently operate precisely on a damaged heart or liver. But this will only be possible once we have a much better understanding of the numbers and nature of our phages, and so many experiments need to be done in order to get to that point.

A famous scientist named Sir Peter Medawar once described viruses as "a piece of bad news wrapped up in a protein," but, in the future, we hope to show that phages are "an opportunity wrapped up in a protein."

\section{ORIGINAL SOURCE ARTICLE}

Shkoporov, A. N., and Hill, C. 2019. Bacteriophages of the human gut: the "known unknown" of the microbiome. Cell Host Microbe 25:195-209. doi: 10.1016/j.chom.2019.01.017

SUBMITTED: 02 July 2019; ACCEPTED: 02 December 2019;

PUBLISHED ONLINE: 23 December 2019.

EDITED BY: Phillip R. Myer, The University of Tennessee, Knoxville, United States

CITATION: Hill C (2019) Bacteriophages: Viruses That Infect Bacteria. Front. Young Minds 7:146. doi: 10.3389/frym.2019.00146

CONFLICT OF INTEREST: The author declares that the research was conducted in the absence of any commercial or financial relationships that could be construed as a potential conflict of interest.

COPYRIGHT @ 2019 Hill. This is an open-access article distributed under the terms of the Creative Commons Attribution License (CC BY). The use, distribution or reproduction in other forums is permitted, provided the original author(s) and the copyright owner(s) are credited and that the original publication in this journal is cited, in accordance with accepted academic practice. No use, distribution or reproduction is permitted which does not comply with these terms. 


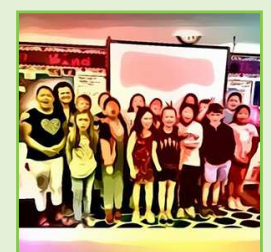

\section{YOUNG REVIEWERS}

\section{JUNALUSKA ELEMENTARY SCHOOL, AGE: 15}

Ms. Fox's third grade class is located in the beautiful mountains of North Carolina!

\section{AUTHOR}

\section{COLIN HILL}

Colin Hill is a Professor of Microbiology at APC Microbiome Ireland who is interested in how our microbiomes may influence our health. He works with lots of talented researchers in his laboratory to study the viruses within the gut, especially the viruses that attack bacteria-bacteriophages. He hopes that in the future we will be able to use bacteriophages to deliberately change the microbiome and improve health of patients with various diseases. ${ }^{*}$ c. hill@ucc.ie 